\title{
MODELAGEM HIDROLÓGICA CHUVA-VAZÃO APLICADA AO ESTUDO DE CHUVAS INTENSAS NA BACIA HIDROGRÁFICA SEMIÁRIDA DO RIO PESQUEIRO (CEARÁ - BRASIL)
}

\author{
Francisco Rodrigo Cunha de Sousa ${ }^{(a)}$, Luis Henrique Magalhães Costa ${ }^{(b)}$, Davis Pereira de \\ Paula ${ }^{(\mathrm{c})}$
}

(a) Mestrado Acadêmico em Geografia, Universidade Estadual Vale do Acaraú, e-mail: rodrigofrcs@ @otmail.com

(b) Curso de Engenharia Civil, Universidade Estadual Vale do Acaraú, e-mail: luishenrique.uva@gmail.com

(c) Centro de Ciência e Tecnologia, Universidade Estadual do Ceará, PROPGEO/UECE, MAG/UVA, davispp@gmail.com

\section{Eixo:GEOTECNOLOGIAS E MODELAGEM ESPACIAL EM GEOGRAFIA FÍSICA}

\begin{abstract}
Resumo
Este estudo, tem por objetivo analisar o comportamento hidrológico da bacia hidrográfica do rio Pesqueiro, localizada no estado do Ceará, diante de eventos extremos de precipitação pluviométrica, através da simulação da vazão no multimodelo hidrológico HEC-HMS. Parte da concepção de que a simulação da vazão é útil para a previsão de impactos ambientais, possibilitando tomar decisões em tempo hábil e contribuir com o planejamento ambiental de bacias hidrográficas (TUCCI, 2001; CHRISTOFOLETTI, 1999), especialmente, aquelas inseridas no contexto semiárido. Foram desenvolvidas análises estatísticas dos dados pluviométricos através de cálculos de medidas de tendência central e dispersão, para fomentar análises probabilísticas capazes de calibrar a equação IDF de eventos extremos de precipitação pluviométrica, que por sua vez deu bases à calibração do HECHMS a partir de dados empíricos coletados historicamente em posto pluviométrico. Os resultados permitiram levantar importantes informações sobre a hidrologia da bacia hidrográfica em questão, apesar da escassez de informações mais detalhadas.
\end{abstract}

Palavras chave: Eventos Pluviométricos Extremos; Modelo Hidrológico; Multimodelo HEC-HMS; Planejamento Ambiental; Bacia Hidrográfica.

\section{Introdução}

O clima do Nordeste brasileiro é predominatemente semiárido, sendo caracterizado, sobretudo, pelas grandes variações temporais e espaciais na distribuição das precipitações pluviométricas, em que se distinguem com muita clareza dois períodos ao longo do ano, sendo um chuvoso e outro de estiagem, que aliado às elevadas temperaturas e consequentes altas taxas de evapotranspiração, ocasionam um quadro de insuficiência hídrica em determinadas áreas (Azevedo et al., 1998). Por outro lado, observam-se elevados picos de precipitação pluviométrica que resultam em volumes excessivos de escoamento superficial em curtos períodos. 
Por outro lado, existem diversas pesquisas que anunciam mudanças substanciais na dinâmica climática brasileira, sendo os processos hidrológicos de bacias hidrográficas, aqueles mais impactados, e consequentemente, interferindo diretamente no cotidiano da sociedade (Freitas, 1994; Naghettini\& Pinto, 2007), exemplo dos diversos fenômenos que são vivenciados atualmente, como eventos de estiagens ou de chuvas intensas prolongadas. Os meios de comunicação e os boletins meteorológicos indicam que os eventos extremos estão cada vez mais frequentes, com a ocorrência de chuvas diárias com volumes equivalentes àqueles previstos para todo um mês, em todas as regiões do país. Também foram vivenciados nos últimos cinco anos, os maiores períodos de estiagens já registrados para região Nordeste como um todo e para parte da região Sudeste, em especial, para São Paulo.

Historicamente, as principais medidas implementadas para amenizar a problemática da escassez hídrica no semiárido brasileiro, sobretudo no estado do Ceará, foram a construção de imensos reservatórios (açudagem) e transposição hídrica por meio de adutoras. Entretanto, algumas destas medidas tornaram-se claramente inviáveis, ao passo que as mudanças climáticas implicaram nos menores índices de precipitação já registrados (nos últimos 108 anos), com cinco anos consecutivos de estiagem e reservatórios abaixo de 7 $\%$ da capacidade total no estado do Ceará (FUNCEME, 2017).

Esta realidade indica ser cada vez mais necessário conhecer o comportamento hidrológico das bacias hidrográficas com a finalidade de prever a ocorrência de eventos extremos, que possam ocasionar prejuízos estruturais (e.g. rompimento de barragens) eimpactos sociais (e.g. refugiados ambientais) (Tucci, 2001; Christofoletti, 1999). Habitualmente, a previsão da distribuição dos recursos hídricos sobre as bacias hidrográficas e sob diferentes condições, utiliza-se de modelos hidrológicos, que possam converter precipitações pluviométricas em vazão, levando em consideração as peculiaridades temporais e espaciais de cada bacia hidrográfica.

Azevedo et al. (1988) ressalta que, desde a década de 1920, são desenvolvidas pesquisas que se baseiam em observar o comportamento climático e prever eventos de estiagem no Nordeste brasileiro através de modelagem matemática dos parâmetros climáticos, entretanto verifica-se uma grande escassez de estudos e metodologias capazes de demonstrar os impactos da variação dos parâmetros climáticos sobre o comportamento hidrológico das bacias hidrográficas semiáridas brasileiras (Freitas, 1994).

Sendo assim, este estudo busca analisar o comportamento hidrológico da bacia hidrográfica do Rio Pesqueiro,localizada no estado do Ceará, diante de eventos extremos de precipitação pluviométrica, através da simulação da vazão, utilizando o multi-modelo hidrológico HEC-HMS, calibrado a partir de análises probabilísticas da série histórica de precipitação diária da área. O uso do HEC-HMS, na modelagem 
hidrológica da bacia hidrográfica do rio Pesqueiro, objetiva sugerir aos órgãos públicos de gestão dos recursos hídricos, uma ferramenta/metodologia que possa auxiliar na tomada de decisões.

\section{Modelos hidrológicos chuva-vazão}

Modelos chuva-vazão representam a relação quantitativa de transformação das precipitações pluviométricas em vazão de uma bacia hidrográfica. Sob esta perspectiva, a bacia hidrográfica é compreendida como o complexo sistema que transforma chuva em vazão e ressalta a premissa de uma modificação significativa no volume total de água, pois parte infiltra ou percola no solo e outra parte pode retornar à atmosfera por evapotranspiração. Também deve ser observado a existência de um atraso na ocorrência da vazão em relação ao tempo de ocorrência da precipitação, ocasionado pelos diversos processos existentes no interior da bacia hidrográfica, como a interceptação e o escoamento superficial e subsuperficial, que por sua vez, estão diretamente relacionados às características do relevo, solos, vegetação e uso e ocupação pela sociedade (Collischonn, 2010).

A relação descrita acima é ilustrada através de um hidrograma, que demonstra a variação do volume de água escoada pelo exutório (ou em outro ponto de interesse) de uma bacia hidrográfica ao longo do tempo, sendo de grande utilidade ao planejamento ambiental, permitindo a previsão de cheias de rios em áreas urbanas e rurais, controle do volume de reservatórios hídricos para melhor aproveitamento para o abastecimento de indústrias, residências e irrigação, entre muitos outras formas de maximizar a gerencia dos recursos hídricos. Sendo assim, a aplicação de modelos hidrológicos à gestão dos recursos hídricos vem se tornando cada vez mais relevante, sobretudo no contexto climático semiárido, cuja escassez hídrica e as mudanças climáticas implicam na necessidade de medidas emergenciais e fundamentais à manutenção das condições básicas de acesso à água pela população.

\subsection{O modelo HEC-HMS}

O HEC-HMS (Hydrologic Engineering Center - Hydrologic Modeling System), é um software desenvolvido pelo Corpo de Engenheiros do Exército dos Estados Unidos (US Army Corps of Engineers) com o objetivo de produzir simulações hidrológicas completas de bacias hidrográficas dendríticas através de modelos físicos, meteorológicos e controladores (USACE-HEC, 2016). 


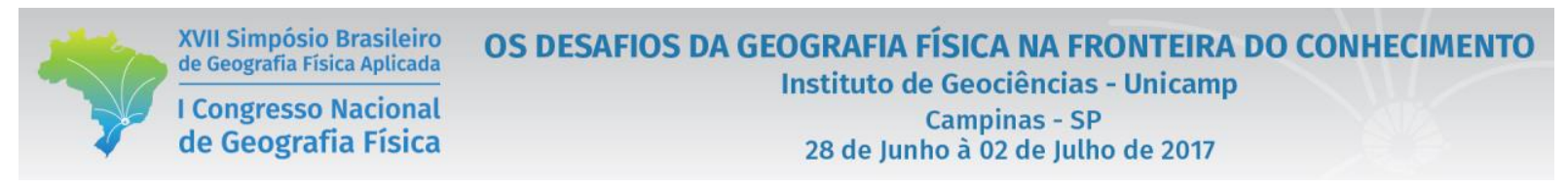

O software inclui módulos procedurais para simular modelos bem tradicionais na hidrologia como hidrogramas unitários, infiltração, evapotranspiração, escoamento superficial e sub-superficial e outros mais recentes que permitem inclusive simulações contínuas de umidade do solo, erosão, transporte de sedimentos e qualidade da água, permitindo o desenvolvimento de quadros hipotéticos de prognose de situações futuras, estimativas e análises de incertezas (Campos, 2009).

O HEC-HMS está estruturado a partir de seis grupos de componentes, que representam as interfaces de entradas de dados e configurações do modelo, sendo eles o gerenciador de bacia, responsável pela entrada de dados descritivos das características físicas da bacia hidrográfica (ou sub-bacias), o gerenciador meteorológico, que recebe as características dos dados de precipitação, o gerenciador de especificação de controle, que define as características do modelo de simulação como a data e hora inicial e final da simulação, o gerenciador de séries históricas, responsável por organizar os dados registrados empiricamente como precipitação, evapotranspiração e temperatura. Além do mais existem o gerenciador de dados em pares, que permite a inserção de dados de fontes diversas e o gerenciador de grades, responsável por importar dados especializados em grades virtuais.

O fluxo de calibração no HEC-HMS (Figura 1) envolve basicamente, (1) a inserção dos dados das séries históricas, (2) definição das características físicas da bacia hidrográfica e seleção dos métodos de transformação, perdas, entre outros, (3) definição das especificações de controle, (4) Especificação das relações entre as formas de precipitações e os postos pluviométricos, (5) simulação pela combinação dos modelos de bacia, meteorológico e controle e (6) visualização e análise dos resultados.

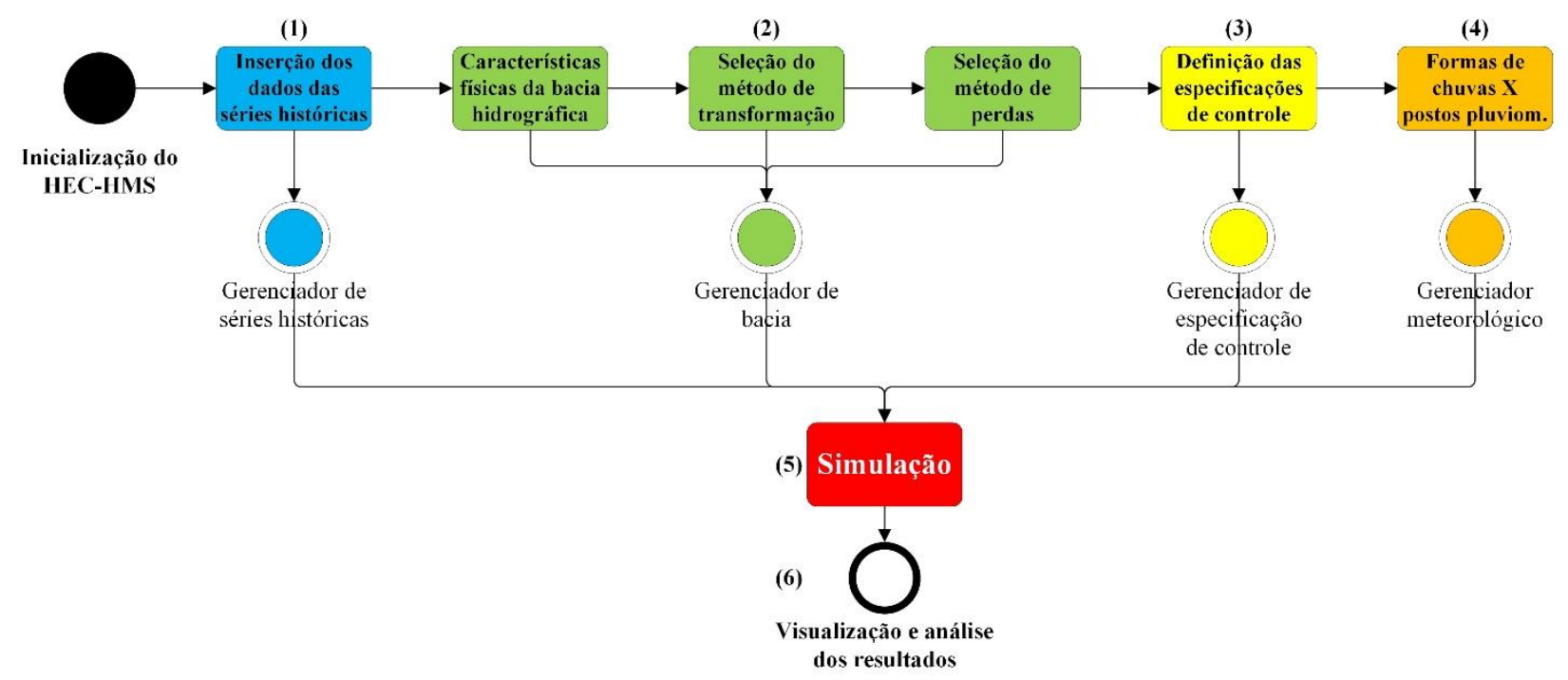

Figura 1 - Fluxo de calibração do HEC-HMS. 


\section{Materiais e métodos}

\section{1. Área de estudo}

A bacia hidrográfica do rio Pesqueiro está inserida no contexto da bacia do rio Coreaú, localizada na porção Noroeste do estado do Ceará, à aproximadamente $250 \mathrm{Km}$ da capital, Fortaleza (Figura 2), cujo principal acesso se dá pela CE-085. Trata-se de uma área de aproximadamente $1.690 \mathrm{Km} 2$ entre as longitudes $40^{\circ} 42^{\prime}$ $53^{\prime \prime} \mathrm{W}$ e $40^{\circ} 14^{\prime} 57^{\prime \prime} \mathrm{W}$ e latitudes $3^{\circ} 83^{\prime} 99^{\prime \prime} \mathrm{S}$ e $2^{\circ} 50^{\prime} 25^{\prime \prime} \mathrm{S}$. A bacia hidrográfica em questão apresenta drenagem direta ao Oceano Atlântico, drenando parcialmente a região onde se encontram os Municípios de Senador Sã, Uruoca, Morrinhos, Marco, Martinópole, Granja, Bela Cruz e Camocim.

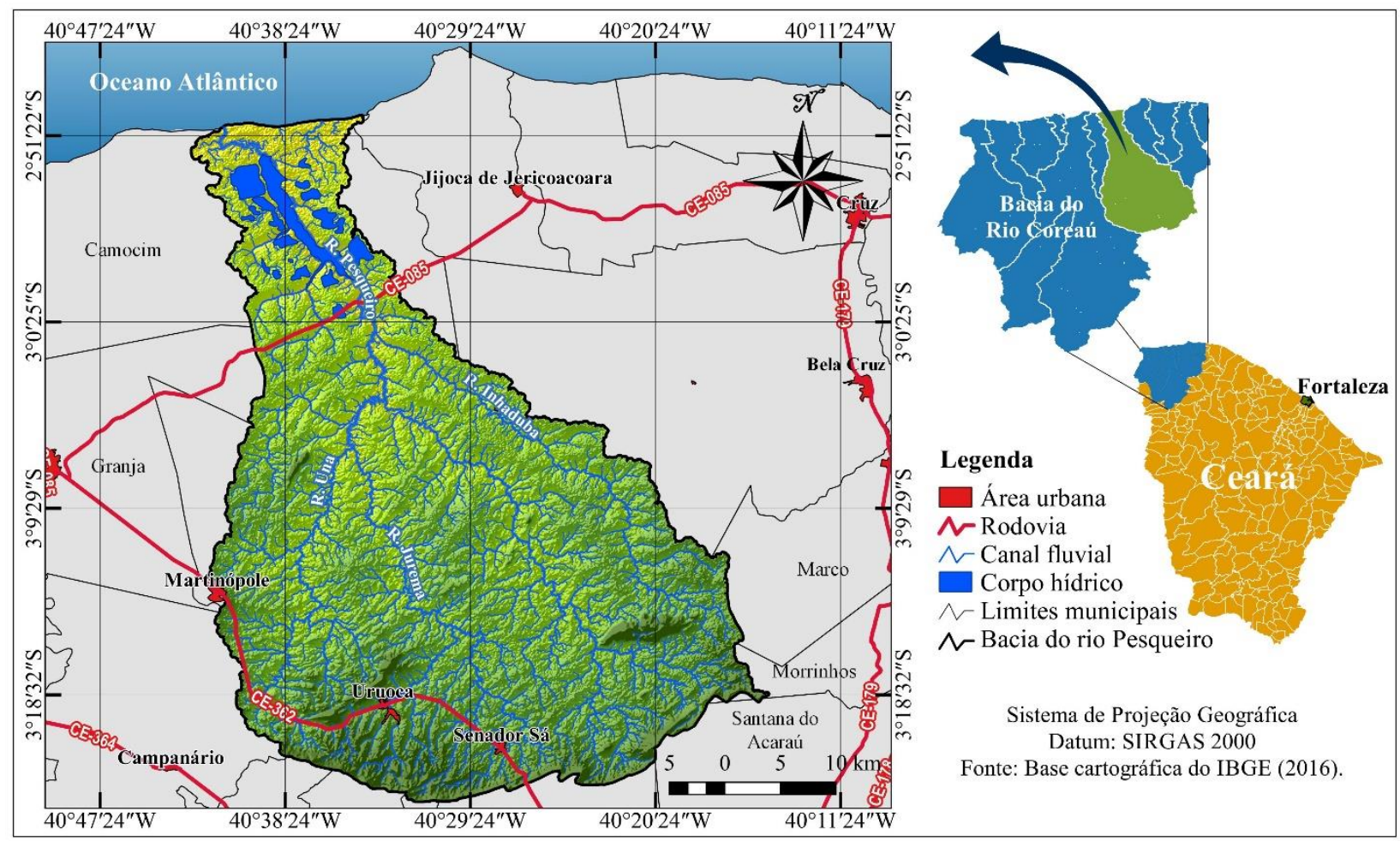

Figura 2 - Mapa de localização da bacia hidrográfica do rio Pesqueiro.

O rio Pesqueiro é o curso hídrico principal da bacia homônima, com comprimento axial de aproximadamente $12 \mathrm{Km}$, formado pela confluência dos rios Jurema e Una à altura do município de Granja, cujas nascentes principais se encontram na "Serra Seca da Gurguéia”, município de Uruoca. O rio Pesqueiro 
tem por principais tributários os rios Tucunduba e Inhaduba pela margem direita e os rios Frios, Cor da Raiz e Cor do Buriti pela sua margem esquerda.

O clima predominante na região é o Clima Equatorial Continental (classificação climática de KöppenGeiger), com precipitações médias anuais abaixo de $1.000 \mathrm{~mm}$, recebendo influencia tanto da sazonalidade da semiaridez do nordeste brasileiro como dos ventos alísios do litoral norte cearense. Sob o

A bacia do rio Pesqueiro apresenta padrão de drenagem dendrítico, com alto grau de ramificação (sexta ordem). A forma de pêra da bacia é o principal fator que lhe confere um reduzido tempo de concentração de deflúvio (ou tempo de transformação da chuva em vazão) e altas probabilidades de enchentes, que apesar das baixas declividades e grande extensão areal, favorece o surgimento e permanecia ao longo do ano, de grandes áreas alagadas no entorno do baixo curso do rio principal.

\subsection{Dados de precipitação}

Os dados de chuvas acumuladas diárias foram obtidos através dos registros do posto pluviométricos mantido e disponibilizado pela Fundação Cearense de Meteorologia (FUNCEME), situado no município deUruoca, na coordenada $3^{\circ} 18^{\prime} 55.6^{\prime}$ S e $40^{\circ} 36^{\prime} 37.2^{\prime}$ W. Este posto possui uma série de dados confiáveis e longa, estando inserido ambientalmente em meio a depressão sertaneja, unidade geomorfológica mais expressiva da bacia.

Inicialmente foi desenvolvida uma análise de consistência dos dados, através de validação básica de limites de valores fisicamente possíveis e adequados às características climáticas da área da pesquisa, posteriormente foi realizada validação temporal, através da comparação dos dados registrados com os dados dos dias anterior e posterior e dos anos anteriores. Também foi desenvolvida validação espacial, através da qual, os dados foram comparados com dados de outros postos vizinhos por meio de técnicas estatísticas como regressão linear, metodologia proposta por Baba et. al. (2014).

Posteriormente foram construídas séries históricas de chuvas acumuladas diárias no período entre 01 de janeiro de 1974 a 31 de dezembro de 2016, portanto, configurando uma série de 43 anos. Para o entendimento do comportamento do regime pluviométrico foram analisados aspectos estatísticos importantes dos dados de chuvas como a média aritmética (equação 1), além do desvio padrão (equação 2) e o coeficiente de variação (equação 3), indispensáveis à identificação de anomalias que possam descaracterizar o regime pluviométrico da área de estudos. 


$$
\bar{X}=\frac{\sum_{i=1}^{n} X i}{n} \quad[1] \quad S=\sqrt{\frac{\sum_{i=1}^{n}(X i-\bar{X})^{2}}{n-1}} \quad \text { [2] } \quad C V=\frac{100 . S}{\bar{X}}
$$

Onde $\underline{X}$ é a média, $\underline{n}$ é o número de elementos da série, $\underline{S}$ é o desvio padrão e $\underline{C V}$ é o Coeficiente de variação. Foram analisadas ainda, a relação intensidade, duração e frequência das precipitações (IDF) através da equação IDF (equação 4), calibrada a partir do método de distribuição probabilística de Gumbel (equação 5), que tem por variáveis a média $(\bar{X})$ e o desvio padrão $(\underline{S})$ das precipitações máximas diárias anuais sugerida por Villela \& Mattos (1975) e uso do suplemento SOLVER do excel 2016, tendo por objetivo o menor Erro Médio Relativo entre os resultados e os eventos de chuva equivalentes propostos pela CETESB (1980).

$$
i=\frac{a \cdot\left(T R^{b}\right)}{(t+c)^{d}} \quad[4] \quad x=\bar{x}-s \cdot\left\{0,45+0,7797 \cdot \ln \left[\ln \left(\frac{T R}{T R-1}\right)\right]\right\}
$$

Onde, $\underline{x}$ é a precipitação máxima, $\underline{T R}$ é o tempo de retorno, $\underline{i}$ é a intensidade da precipitação e $\underline{t}$ é o tempo total do evento de precipitação, $a, b, c$ e $d$ são as variáveis da equação a serem calibradas.

\subsection{Calibração do HEC-HMS}

A série histórica simulada foi calibrada a partir do hietograma unitário, dado pela chuva efetiva, ou seja, a parte da precipitação que gerou escoamento superficial, da bacia hidrográfica do rio Pesqueiro. O hietograma foi construído conforme o método de blocos alternados, que tem por base a distribuição da precipitação total, cujo tempo é dado pelo maior tempo de retorno da bacia (TR), em blocos de intervalos iguais dados pela aplicação da equação IDF (equação 4) após calibração para os dados da área de estudo.

O modelo físico da bacia foi calibrado conforme dados levantados através de Sistema de Informação Geográfica (SIG), como área, perímetro, comprimento do rio principal, declividade, área impermeável, tipologia de solos, entre outros. O método SCS Curve Number foi selecionado para simular as perdas, enquanto o método SCS Unit Hidrograph foi selecionado para simular a transformação de precipitação em vazão. Estes métodos de simulação levam em consideração as características dos solos, os tipos de usos e coberturas. 


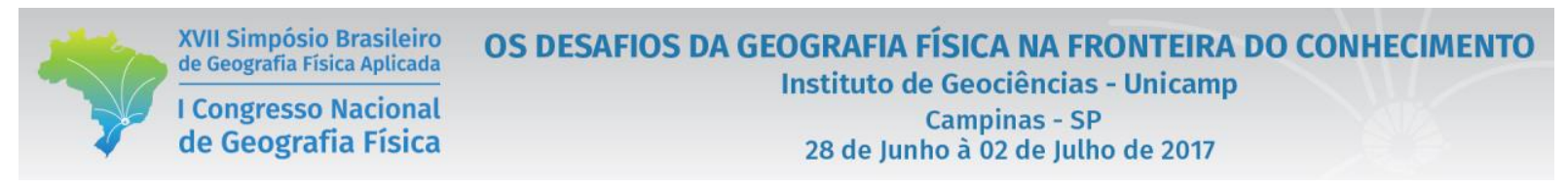

Por sua vez, a definição das especificações de controle levou em consideração um período hipotético equivalente ao tempo de concentração da bacia hidrográfica, dado pela equação de Whatt e Chow (equação $6)$.

$$
T c=7,68 \cdot\left(\frac{L}{S^{0,5}}\right)^{0,79}
$$

Onde, $\underline{T C}$ é o tempo de concentração, $\underline{L}$ é o comprimento do canal de drenagem principal e $\underline{s}$ é a declividade média do canal de drenagem principal.

\section{Resultados e discursão}

\subsection{Calibração da equação IDF}

As curvas IDF das chuvas máximas para o posto pluviométrico situado no município de Uruoca, obtidas através do método de Gumbel (equação 4) apresentaram resultados esperados, a medida que não diferem muito daqueles apresentados pela literatura. Por sua vez, a calibração dos dados, levando em consideração o menor Erro Médio Relativo (EMR) entre os resultados e os eventos de chuva equivalentes propostos pela CETESB (1980) renderam ótimos resultados, com EMR igual a 2,03 (tabela 1) e correlação igual a 0,9993, portanto bem próximo a 1, o que ressalta a existencia de uma correlação entre os dois conjuntos de dados muito boa.

Tabela 1 - Intensidades máximas ( $\mathrm{mm}$ ) para diferentes tempos de retorno resultantes da aplicação do método de Gumbel (A) e após a calibração (B).

\begin{tabular}{|c|c|c|c|c|c|c|c|c|c|c|c|c|}
\hline \multirow{3}{*}{ DURAÇÃO } & \multicolumn{6}{|c|}{ A } & \multicolumn{6}{|c|}{ B } \\
\hline & \multicolumn{6}{|c|}{ Tempo de retorno (anos) } & \multicolumn{6}{|c|}{ Tempo de retorno (anos) } \\
\hline & 5 & 10 & 15 & 25 & 50 & 100 & 5 & 10 & 15 & 25 & 50 & 100 \\
\hline $24 \mathrm{~h}$ & 5,39 & 6,48 & 7,10 & 7,86 & 8,88 & 9,9 & 5,73 & 6,56 & 7,10 & 7,84 & 8,98 & 10,28 \\
\hline $12 \mathrm{~h}$ & 9,16 & 11,02 & 12,07 & 13,36 & 15,1 & 16,83 & 9,64 & 11,04 & 11,94 & 13,20 & 15,11 & 17,30 \\
\hline $10 \mathrm{~h}$ & 10,61 & 12,76 & 13,97 & 15,47 & 17,49 & 19,49 & 11,05 & 12,65 & 13,69 & 15,12 & 17,31 & 19,82 \\
\hline $8 \mathrm{~h}$ & 12,61 & 15,17 & 16,61 & 18,40 & 20,79 & 23,17 & 13,04 & 14,93 & 16,16 & 17,85 & 20,44 & 23,40 \\
\hline $6 \mathrm{~h}$ & 15,53 & 18,67 & 20,45 & 22,64 & 25,59 & 28,52 & 16,13 & 18,46 & 19,99 & 22,08 & 25,28 & 28,94 \\
\hline $1 \mathrm{~h}$ & 54,36 & 65,36 & 71,57 & 79,27 & 89,58 & 99,82 & 56,19 & 64,33 & 69,63 & 76,94 & 88,08 & 100,84 \\
\hline $30 \mathrm{~min}$ & 80,45 & 96,74 & 105,9 & 117,3 & 132,6 & 147,7 & 84,61 & 96,87 & 104,85 & 115,84 & 132,63 & 151,85 \\
\hline $25 \mathrm{~min}$ & 87,85 & 105,6 & 115,7 & 128,1 & 144,8 & 161,3 & 93,15 & 106,65 & 115,44 & 127,54 & 146,02 & 167,18 \\
\hline $15 \mathrm{~min}$ & 112,6 & 135,4 & 148,3 & 164,2 & 185,6 & 206,8 & 118,30 & 135,44 & 146,60 & 161,97 & 185,44 & 212,31 \\
\hline $10 \mathrm{~min}$ & 130,3 & 156,7 & 171,6 & 190,1 & 214,8 & 239,3 & 138,16 & 158,18 & 171,21 & 189,17 & 216,57 & 247,95 \\
\hline $5 \mathrm{~min}$ & 164,1 & 197,4 & 216,1 & 239,3 & 270,5 & 301,4 & 167,95 & 192,29 & 208,13 & 229,95 & 263,27 & 301,41 \\
\hline
\end{tabular}


Com a calibração dos parâmetrosa, b, c e d, foi possível definir umaequação IDF para a bacia do rio Pesqueiro (Equação 7). Vale destacar que essa é a primeira determinação desse tipo de esquação para essa bacia hidrográfica.

$$
i=\frac{1062,13 \cdot\left(T R^{0,1592}\right)}{(t+12,085)^{0,7605}}
$$

Essa equação permite calcular o valor da intensidade máxima (em $\mathrm{mm} / \mathrm{hora}$ ) de uma precipitação pluviométrica, levando-se em consideração sua duração (em minutos) e o tempo de retorno (em anos), entretanto deve ser observado que esta equação é suscetível a erros, pois foi levado em consideração o menor erro médio relativo, o que distanciou um pouco a correlação da unidade, apesar dos resultados mostraremse bastante satisfatórios.Considerando-se o tempo de retorno da bacia (dado pelo tempo de retorno da maior precipitação da série, ou seja, 212,8 mm) igual a 100 anos e o tempo de concentração igual a 121,43 minutos (equação 6), foi construído o hietograma da chuva de projeto da bacia apresentado na figura 3.

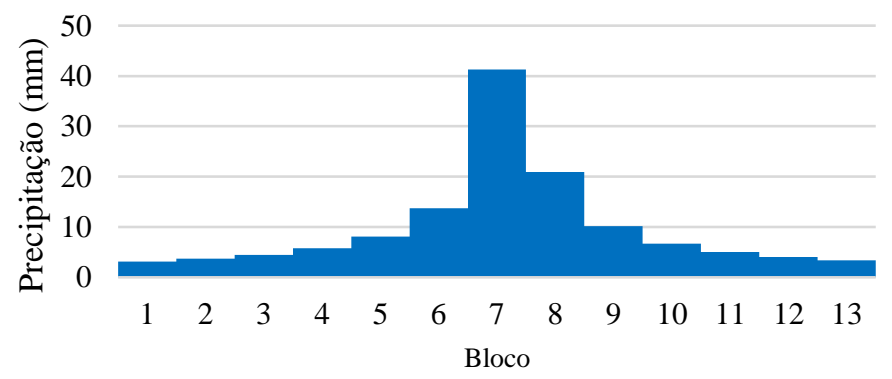

Figura 3 - Hietograma da chuva de projeto da bacia hidrográfica do rio Pesqueiro.

\subsection{Simulação da vazão}

A aplicação do HEC-HMS permitiu o levantamento de importantes dados sobre o comportamento da bacia hidrográfica do rio Pesqueiro (tabela 2), revelando informações como volume de precipitação de 223.035,3 (1.000m3) para os dados simulados, sendo grandes as perdas por evapotranspiração de 60.270,5 (1.000m3), com volume total escoado de apenas $162.764,8$ (1.000m3), ou seja, durante um evento de precipitação pluviométrica intensa de aproximadamente 130 minutos, foi possível observar uma perda de aproximadamente $27 \%$ do volume total precipitado.

O pico de descarga de vazão se deu aproximadamente 3 horas e 20 minutos após o início da precipitação com volume de 18.637,5 m3/s, o que é bastante representativo das características morfométricas da bacia e 


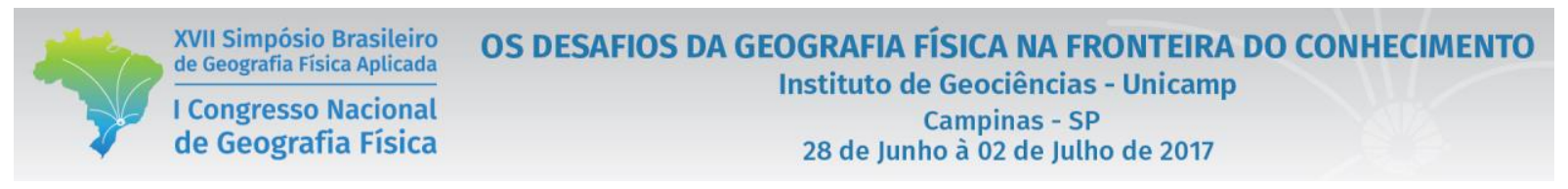

do regime de precipitação do clima semiárido, pois trata-se de um volume de aproximadamente 1.000.000 m3 por minuto, isto é, um volume bastante elevado para o curto período.

Tabela 2 -Parâmetros de simulação do modelo chuva-vazão da bacia do rio Pesqueiro.

\begin{tabular}{l|l}
\hline PARÂMETRO & VALOR \\
\hline Tempo total de simulação & $10 \mathrm{~h}$ \\
\hline Tempo de especificação para controle & $10 \mathrm{~min}$ \\
\hline Pico de descarga de precipitação & $18.637,5 \mathrm{~m}^{3} / \mathrm{s}$ \\
\hline Tempo do pico de descarga & 3 horas e 20 minutos \\
\hline Volume de precipitação & $223.035,3\left(1.000 \mathrm{~m}^{3}\right)$ \\
\hline Volume de escoamento & $162.764,8\left(1.000 \mathrm{~m}^{3}\right)$ \\
\hline Volume de perdas por evapotranspiração & $60.270,5\left(1.000 \mathrm{~m}^{3}\right)$ \\
\hline Volume de descarga no exutório & $162.764,8\left(1.000 \mathrm{~m}^{3}\right)$ \\
\hline
\end{tabular}

Ao observar o gráfico da figura 4, é possível constatar que mais de $90 \%$ de todo o volume da vazão se deu nas três horas que seguiram o final da precipitação. Vale destacar, ainda, o reduzido tempo de recessão observado na simulação, ou seja, o tempo que segue o fim do escoamento superficial, de aproximadamente 1 hora, variável que denota o curto periodo de permanencia do volume precipitado no interior da bacia e consequentemente desfavorece processos naturais importantes como a infiltração.

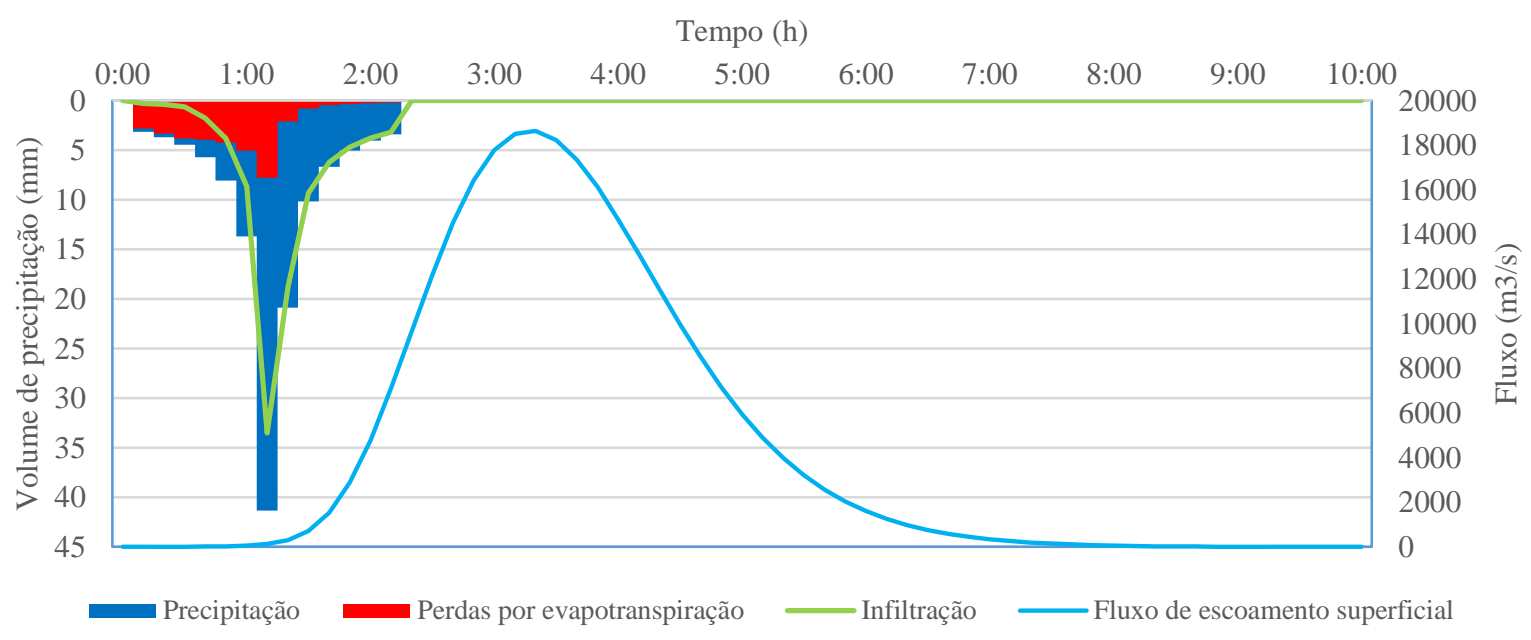

Figura 4 - Hidrograma unitário da bacia hidrográfica do rio Pesqueiro.

Outra informação relevante é o intervalo de tempo entre os picos de descarga de precipitação e vazão, que para a simulação foi de 2 horas e 20 minutos, o que representa um tempo bastante reduzido para tomadas 
de decisões, entretanto diante de um monitoramento em tempo contínuo/síncrono é possível prever situações emergenciais e lançar alertas às autoridades competentes e à população.

\section{Considerações finais}

Por meio de recursos estatísticos foram desenvolvidas análises da série histórica de precipitações pluviométricas, que possibilitaram a calibração da equação IDF e posteriormente a construção do hietograma unitário representativo dos eventos extremos de precipitações pluviométricas da área da pesquisa. A calibração do modelo HEC-HMS com os dados da série histórica de precipitação e com as características físicas da bacia permitiu levantar informações relevantes sobre o ciclo hidrológico da área.

Sendo assim, é possível considerar, portanto, que o HEC-HMS é útil aos estudos em bacias hidrográficas semiáridas brasileiras, e aliado à metodologia desenvolvida possibilita simular a vazão e os processos hidrológicos a partir de registros de precipitação diárias,apesar da escassez de dados de séries históricasmais detalhadas de precipitação, permitindo compreender o comportamento geral da água precipitada no interior da bacia hidrográfica.

Entretanto éválido observar que as análises desenvolvidas nesta pesquisa apresentam algumas limitações por tratar-se de bases probabilísticas, porém, diante da escassez de informações mais detalhadas, o conhecimento do hidrograma e da dinâmica hidrológica de eventos de precipitações extremos é indispensável ao planejamento de uso dos recursos hídricos, seja no dimensionamento de obras hidráulicas ou na garantia da segurança hídrica à sociedade. Além do mais, é importante observar também a necessidade de aprimoramento do modelo por meio de uma simulação contínua, inserção de outras variáveis e ampliação à outras bacias hidrográficas semiáridas.

\section{Bibliografia}

AZEVEDO, P. V; SILVA, B. B; RODRIGUES, M. F. Previsão Estatística das Chuvas de Outono no Estado do Ceará. Rev. Bras. de Meteor., v. 13, no. 1, São Paulo, 1988, p. 19-30.

BABA, R. K; VAZ, M. S. M. G; COSTA, J. Correção de dados agrometeorológicos utilizando métodos estatísticos. Rev. Bras. de Meteor., v. 29, no. 4, São Paulo, 2014. p. 515-526.

CAMPOS, J. N. Lições em modelos e simulação hidrológica. Fortaleza: Expressão gráfica, 2009. 
CHRISTOFOLETTI, Antônio. Modelagem de sistemas ambientais. São Paulo: Blucher, 1999.

COLLISCHONN, W; TASSI, R. Introduzindo hidrologia. IPH-UFRGS, 2010.

CETESB. Departamento de Água e Energia Elétrica-Companhia de Tecnologia de Saneamento Ambiental. Drenagem urbana: Manual de projeto. São Paulo: DAEECETESB, 1980.

FREITAS, M. A. S. Modelos diários chuva-vazão em bacias do semi-árido brasileiro. Revista Tecnologia, n. 1, dez, 1994. p. 31-38.

FUNCEME - Fundação Cearense de Meteorologia e Recursos Hídricos. Postos Pluviométricos. Disponível em: <http://www.funceme.br>. Acesso em: 05 de janeiro de 2017.

NAGHETTINI, M; PINTO, E. J. A. Hidrologia Estatística. Serviço Geológico do Brasil - CPRM, Agosto 2007.

TUCCI, C.E.M. Hidrologia: ciência e aplicação. Porto Alegre: UFRGS/Edusp/ABRH, 2001.

US ARMY CORPS OF ENGINEERS - HYDROLOGIC ENGINEERING CENTER. HEC-HMS, Hydrologics Modeling System, User's Manual, Version 4.2. Califórnia: Agosto de 2016.

VILLELA, S. M.; MATTOS, A. Hidrologia aplicada. São Paulo: McGraw-Hill do Brasil,1975.

\section{Agradecimentos}

Ao Mestrado Acadêmico em Geografia da Universidade Estadual Vale do Acaraú, por todo o apoio; e à CAPES, pela concessão da bolsa durante o período de estudos. 